\title{
Updated recommendation on molecular-targeted therapy for metastatic renal cell cancer
}

\author{
SENJI HOSHI ${ }^{1,2}$, KENJI NUMAHATA ${ }^{1}$, HIDENORI KANNO ${ }^{1}$, MASAHIKO SATO $^{1}$, AKIHITO KUROMOTO ${ }^{1}$, \\ KUNIHISA NEZU ${ }^{1}$, TAKANARI SAKAI ${ }^{1}$, CHIHITO KONNO $^{3}$, YUICHI ISHIZUKA ${ }^{3}$, HIDEAKI IZUMI ${ }^{3}$, \\ KATSUYUKI TAGUCHI ${ }^{3}$, KUNIO ONO ${ }^{3}$, KIYOTSUGU HOSHI ${ }^{2}$, SATOSHI KANTO ${ }^{2}$, RIKA TAKAHASHI ${ }^{4}$, \\ BILIM VLADIMIR $^{5}$, NAOE AKIMOTO ${ }^{6}$, ISOJI SASAGAWA ${ }^{2}$ and SHOICHIRO OHTA ${ }^{6}$
}

\author{
${ }^{1}$ Department of Urology, Yamagata Prefectural Central Hospital, Yamagata 990-2292; ${ }^{2}$ Department Urology, \\ Yamagata Tokushukai Hospital, Yamagata 990-0834; ${ }^{3}$ Department of Urology, Ishinomaki Red Cross Hospital, Ishinomaki, \\ Miyagi 986-8522; ${ }^{4}$ Department of Rehabilitation, Yamagata Tokushukai Hospital, Yamagata 990-0834; ${ }^{5}$ Department of Urology, \\ Niigata Prefectural Cancer Center Hospital, Niigata 951-8566; ${ }^{6}$ Clinical Pathology, Faculty \\ of Pharmaceutical Sciences, Josai University, Sakado, Saitama 350-0295, Japan
}

Received April 9, 2016; Accepted July 31, 2017

DOI: $10.3892 / \mathrm{mco} .2017 .1371$

\begin{abstract}
Molecular-targeted therapy was recommended for the systemic therapy of renal cell cancer (RCC) in the RCC guidelines, but these guidelines do not address the order of administration of the multiple presently available agents. There are several aspects that remain unknown regarding the optimal administration order and combination of molecular-targeted drugs. Until the optimal treatment sequence is determined by clinical trials, treatment individualization is required for each patient based on patient and disease characteristics. We herein investigate 12 cases of RCC patients who received axitinib. Axitinib was used as the first-line drug in 4 cases, second-line in 5 cases, third-line in 1 case and as a fourth-line drug in 2 cases. Partial response (PR) was observed in 4 cases (30\%) and stable disease in 4 cases $(30 \%)$ during axitinib treatment, with an overall response rate of $60 \%$. The duration of PR ranged from 6 to 19 months. Based on our cases, axitinib exhibited reasonable therapeutic efficacy as first- as well as second-line treatment. However, more cases are required to draw firm conclusions.
\end{abstract}

\section{Introduction}

Molecular-targeted therapy was recommended for the systemic therapy of renal cell cancer (RCC) in the 2011 Japanese Urological Association RCC guidelines $(1,2)$; however, these guidelines do not address the order of administration of presently available multiple agents. The European Association of Urology guidelines recommend either sunitinib

Correspondence to: Professor Shoichiro Ohta, Clinical Pathology, Faculty of Pharmaceutical Sciences, Josai University, 1-1 Keyakidai, Sakado, Saitama 350-0295, Japan

E-mail: sohtajp@josai.ac.jp

Key words: renal cancer, tyrosine kinase inhibitor, axitinib or everolimus as first-line therapy, and sorafenib or everolimus as second-line therapy, although there are several aspects that remain unknown regarding the optimal administration order and combination of the multiple molecular-targeted drugs (3). At the 2015 ASCO annual meeting, the results of a comparison test of sunitinib $\rightarrow$ everolimus vs. everolimus $\rightarrow$ sunitinib were reported, indicating that the median survival rates were 29.5 and 22.2 months, respectively, concluding that sunitinib $\rightarrow$ everolimus was more effective $(4,5)$.

Until clinical trials determine the optimal treatment sequence, treatment individualization is required for each patient based on patient and disease characteristics. In this study, we investigated 12 cases of renal cancer in which axitinib had been administered.

\section{Patients and methods}

Case series. A total of 12 patients who were diagnosed with RCC between 2005 and 2011 were reviewed (Table I). Approval was obtained from the Ethics Committee of our institution at the commencement of the study. The patients included 9 men and 3 women, with a mean age of 66 years (range, 58-79 years). Axitinib was used as a first-line drug in 4 cases, second-line in 5 cases, third-line in 1 case and as a fourth-line drug in 2 cases. Partial response (PR) was observed in 4 cases $(30 \%)$ and stable disease in 4 cases $(30 \%)$ during axitinib treatment, with an overall response rate of $60 \%$. The duration of PR ranged from 6 to 19 months.

Of the 4 PR cases, the case 1 patient had received axitinib as first-line therapy, and he had not received any other molecular-targeted drugs; in 2 PR cases, axitinib was administered as second-line treatment; in the remaining PR case, axitinib had been followed by panitumab, with which a clinical response was achieved.

Case reports. Case 6 was a 61-year-old male patient. At the initial visit, an $8-\mathrm{cm}$ mass was identified, extending from 
Table I. Summary of the investigated 12 cases.

\begin{tabular}{|c|c|c|c|c|c|c|}
\hline $\begin{array}{l}\text { Case } \\
\text { no. }\end{array}$ & $\begin{array}{l}\text { Age, } \\
\text { years }\end{array}$ & Sex & Drugs (sequence) & Metastastic sites & Effectiveness & $\begin{array}{l}\text { PR duration, } \\
\text { months }\end{array}$ \\
\hline 1. & 79 & Male & A & Lung, adrenal & PR & 6 \\
\hline 2. & 59 & Male & $\mathrm{Su} \rightarrow \mathrm{A} \rightarrow \mathrm{E}$ & Lung, bone & PD & \\
\hline 3. & 73 & Male & $\mathrm{Su} \rightarrow \mathrm{A}$ & Lung, liver & PR & 9 \\
\hline 4. & 69 & Male & $\mathrm{Su} \rightarrow \mathrm{A}$ & Kidney, lung, pancreas & PR & 6 \\
\hline 5. & 47 & Male & $\mathrm{INF} \rightarrow \mathrm{Su} \rightarrow \mathrm{A}$ & Lung, lymph nodes & SD & \\
\hline 6. & 61 & Male & $\mathrm{A} \rightarrow \mathrm{P}$ & Bone, pleural cavity & PR & 19 \\
\hline 7. & 58 & Female & $\mathrm{Su} \rightarrow \mathrm{A}$ & Lung, lymph nodes, brain, bone & PD & \\
\hline 8. & 76 & Female & $\mathrm{Su} \rightarrow \mathrm{A}$ & Liver & SD & \\
\hline 9. & 76 & Female & $\mathrm{INF} \rightarrow \mathrm{So} \rightarrow \mathrm{UFT} \rightarrow \mathrm{A}$ & Lung, lymph nodes & SD & \\
\hline 10. & 64 & Male & $\mathrm{A} \rightarrow \mathrm{E} \rightarrow \mathrm{INF} \rightarrow \mathrm{Su} \rightarrow \mathrm{So}$ & Adrenal, pancreas & PD & \\
\hline 11. & 67 & Male & $\mathrm{GC} \rightarrow \mathrm{GDC} \rightarrow \mathrm{E} \rightarrow \mathrm{A}$ & Lung, liver, bone & $\mathrm{SD} \rightarrow \mathrm{PD}$ & $\begin{array}{l}8 \text { (SD, collecting } \\
\text { ductal carcinoma) }\end{array}$ \\
\hline 12. & 63 & Male & $\mathrm{A}$ & Bone, lung & PD & \\
\hline
\end{tabular}

A, axitinib; Su, sunitinib; E, everolimus, INF, interferon; So, sorafenib; P, pazopanib; GC, gemcitabine and carboplatin; GDC, gemcitabine, docetaxel and carboplatin; PR, partial response; PD, progressive disease; SD, stable disease.
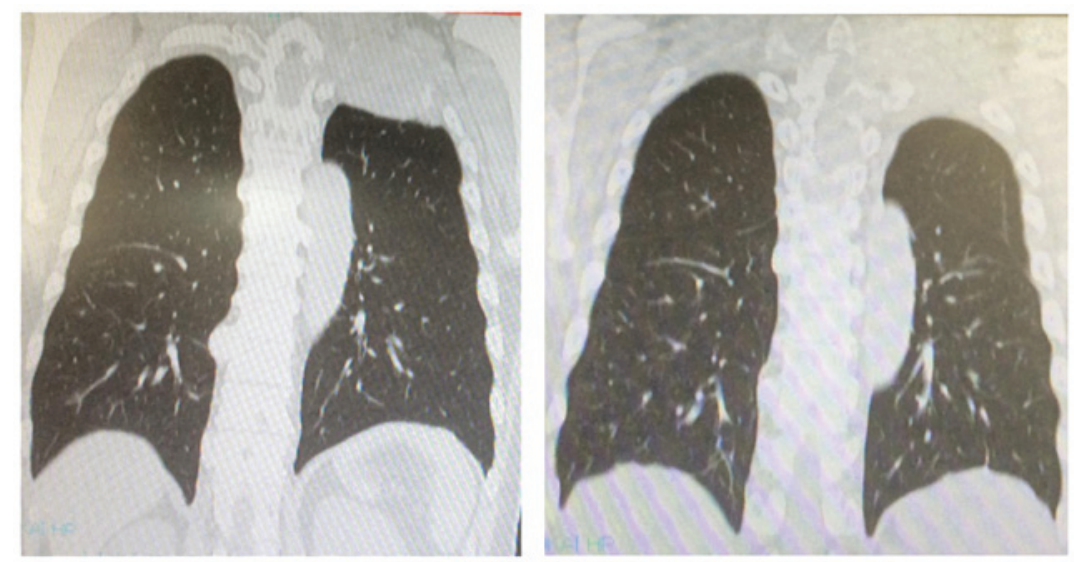

Figure 1. Case 6: Computed tomography revealed a 3-cm tumor in the inferior pole of the right kidney (left panel, pretreatment; right panel, post-treatment).
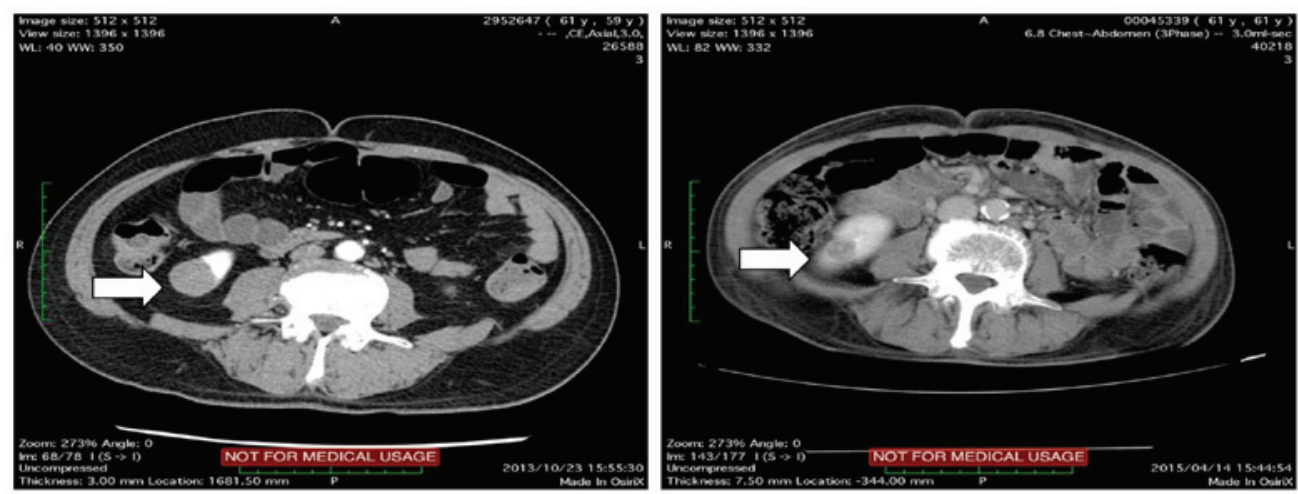

Figure 2. Case 6: Computed tomography revealed that, although the renal lesion was reduced, the bone metastatic lesion exhibited progression (left panel, pretreatment; right panel, post-treatment).

the posterior aspect of the upper left lung to the chest wall, infiltrating the ribs and the Th1 vertebral body, with partial compression of the spinal cord. The computed tomography (CT) scan revealed a 3-cm tumor in the inferior pole of the 
right kidney (Fig. 1). CT-guided tumor biopsy of the lung mass revealed RCC metastasis. Axitinib was administered at $10 \mathrm{mg} /$ day; after 10 days, the dose was increased to $12 \mathrm{mg} /$ day, and to $14 \mathrm{mg} /$ day 2 weeks later. At the time of admission to the hospital the patient was bedridden. Following intensive rehabilitation, the patient was able to use a wheelchair and even to leave his house. The treatment was continued on an outpatient basis. However, due to progression of metastatic bone disease (Fig. 2), the patient was readmitted to the hospital. He currently remains alive and is on pazopanib treatment.

We encountered one case of collecting duct carcinoma, which is a type of RCC refractory to cytotoxic and molecular-targeted therapy. However, case 11, a 67-year-old male patient, achieved PR. The patient visited our hospital complaining of hematuria. Based on the results of the pathology, he was diagnosed with renal collecting duct carcinoma with renal hilar lymph node metastasis. After 4 months, the patient underwent left nephrectomy and the subsequent pathological diagnosis was pT3, ly1, v1, INF $\beta$, pN2. Four weeks after the operation, the patient was started on adjuvant GC chemotherapy (gemcitabine 1,200 mg and cisplatin $300 \mathrm{mg}$ ) (6) and completed four cycles. Six months postoperatively, multiple pulmonary metastases were identified on $\mathrm{CT}$, and metastasis to the right pelvic bone was identified by bone scintigraphy. GDC chemotherapy (gemcitabine 1,200 mg, docetaxel $80 \mathrm{mg}$ and cisplatin $300 \mathrm{mg}$ ) was initiated 4 weeks later (7). The results of the CT conducted on June 20, 2012 confirmed peritoneal dissemination, progression of multiple lung metastases and revealed metastatic liver disease. Two months later the patient was administered $10 \mathrm{mg}$ everolimus. After administration of everolimus for 3 months, the blood sugar level was found to be high, which was considered to be an adverse event (AE) and the drug was discontinued, followed by normalization of the patient's blood sugar levels, after which time everolimus was resumed at a reduced dose of $5 \mathrm{mg}$. At the 8-month follow-up the patient remained progression-free, which is unusually long for renal collecting duct cancer.

\section{Discussion}

Based on our cases, axitinib demonstrated reasonable therapeutic efficacy as first- as well as second-line treatment. However, to draw a firm conclusion, more cases must be accumulated.

Procopio et al reviewed 13 cases of renal collecting duct carcinoma. Renal collecting duct carcinoma patients (median age, 57 years) comprise $3.4 \%$ of all metastatic RCC (mRCC) patients, with a median survival time of 4 months, with only 3 cases having survived 6-33 months (8-11). The disease-specific survival of our patient (case 11) was 13 months from the time of the appearance of metastases. In a study on the administration of sunitinib, axitinib, sorafenib, interferon and temsirolimus as first-line drugs in 4,736 mRCC cases, a reduction ratio of $>7-8 \%$ of the tumor was associated with a relatively good prognosis (12). Moreover, in a study on the combined use of tyrosine kinase inhibitors (TKIs) and mammalian target of rapamycin inhibitors in 153 cases of metastatic clear cell RCC (ccRCC), comparing the combined use of lenvatinib and everolimus with the use of lenvatinib alone and with the use of everolimus alone, achieved a survival of 13.1, 7.5 and 8.5 months, respectively, indicating that combination therapy was superior to single-agent treatment (13). Furthermore, in a study of 108 cases of non-ccRCC, survival with sunitinib was 8.3 months and that with everolimus 5.6 months, indicating that sunitinib was superior; however, for poor-risk RCC, survival was 4.0 and 6.1 months for sunitinib and everolimus, respectively, indicating that everolimus was better for poor-risk cases (14).

A study of the programmed cell death protein-1 (PD-1) antibodies for RCC was also conducted (15-17). The therapeutic effects of pazopanib and sunitinib in RCC cases expressing PD-1 were significantly inferior to the PD-1 low-expressing cases, and the median survival time was also shorter (18). Nivolumab (PD-1-inhibiting antibodies) was investigated in 91 cases, and it was effective in programmed death-ligand-1 (PD-L1)-positive as well as -negative cases (based on immunostaining of cancer cells). While a $71 \%$ 1-year survival was attained by both positive and negative cases, the 2-year survival rates were 64 and $48 \%$, respectively (19). In addition, the mPFS of the cases in whom anti-PD-1 treatment had not been effective and in whom TKIs had been administered was 6.9 months, indicating that it may be safely administered (20). Immunostaining for PD-L1 was positive in $51 \%$ of spindle cell cancer cases, whereas $100 \%$ of the cases that contained a ccRCC component were positive (18). However, due to the fact that only $17 \%$ of the ccRCCs that did not contain a spindle cell carcinoma component were PD-L1 positive, there is a possibility that PD-1 antibodies are effective in spindle cell cancer, which has poor prognosis (21). A study to predict therapeutic effect based on immunostaining for PD-L1 of tumor cells has been conducted. However, cases were successfully treated irrespective of positive or negative immunostaining; thus, no conclusion was reached at that time (22). Moreover, it is considered that the more gene mutations the cancer cells harbour, the more successful the immunotherapy. Further research on immune therapy that includes PD-L1 antibodies is expected in the near future.

\section{References}

1. Naito S, Tatsugami K, Shinohara N, Tomita Y, Mizokami A, Fujisawa M, Hashine K, Nishikido M, Nakagawa M, Tsukamoto T and Akaza H: Final results of a phase II study of S-1 in patients with cytokine-refractory metastatic renal cell carcinoma. Jpn J Clin Oncol 44: 122-126, 2014.

2. Japanese Urological Association: Guideline on renal cell carcinoma 66-75, 2011. http://www.urol.or.jp/info/guideline/ data/07_kidney_cancer_2011.pdf. Accessed March 17, 2015.

3. Ljungberg B, Albiges L, Bensalah K, Bex A, Giles RH, Hora M, Kuczyk MA, Lam T, Marconi L, Merseburger AS, Powles T, et al: Guideline on renal cell carcinoma. European Association of Urology. http://uroweb.org/wp-content/uploads/10-Renal-CellCarcinoma_LR1.pdf. Accessed March 17, 2015.

4. Knox JJ, Barrios CH, Kim TM, Cosgriff T, Srimuninnimit V, Pittman K, Sabbatini R, Rha SY, Flaig TW, Page RD, et al: Final overall survival analysis for the phase II RECORD-3 study of firstline everolimus followed by sunitinib versus first-line sunitinib followed by everolimus in metastatic RCC. Ann Oncol 28: 1339-1345, 2017.

5. Motzer RJ, Barrios CH, Kim TM, Falcon S, Cosgriff T, Harker WG, Srimuninnimit V, Pittman K, Sabbatini R, Pha SY, et al: Phase II randomized trial comparing sequential first-line everolimus and second-line sunitinib versus first-line sunitinib and second-line everolimus in patients with metastatic renal cell carcinoma. J Clin Oncol 32: 2765-2771, 2014.

6. Yoshinaga A and Kamata S: Long survival in a patient with advanced ureteral carcinoma treated with TIN Regimen (Paclitaxel, Ifosfamide, Nedaplatin) and Radiotherapy: A Case Report. Hinyokika Kiyo 60: 435-437, 2014 (In Japanese). 
7. Hoshi S, Ohyama C, Ono K, Takeda A, Yamashita S, Yamato T, Itoh A, Satoh M, Saito S, Okada Y, et al: Gemcitabine plus carboplatin; and gemcitabine, docetaxel and carboplatin combined chemotherapy regimens in patients with metastatic urothelial carcinoma previously treated with a platinum-based regimen: Preliminary report. Int J Clin Oncol 9: 125-129, 2004.

8. Procopio G, Testa I, Iacovelli R, Grassi P, Verzoni E, Garanzini E, Colecchia M, Torelli T and De Braud F: Treatment of collecting duct carcinoma: Current status and future perspectives. Anticancer Res 34: 1027-1030, 2014.

9. Biondani P, Verzoni E, Torri V, Porcu L, Grassi P, Testa I, DE Braud F and Procopio G: Sequential tyrosine kinase inhibitors (TKIs) in metastatic renal cell carcinoma: Results from a large cohort of patients. Anticancer Res 34: 2395-2398, 2015.

10. Bracarda S, Castellano D, Procopio G, Sepúlveda JM, Sisani M, Verzoni E and Schmidinger M: Axitinib safety in metastatic renal cell carcinoma: Suggestions for daily clinical practice based on case studies. Expert Opin Drug Saf 13: 497-510, 2014.

11. Procopio G, Verzoni E, Biondani P, Grassi P, Testa I, Garanzini E and de Braud F: Rationale and protocol of RESORT, a randomized, open-label, multicenter phase II study to evaluate the efficacy of sorafenib in patients with advanced renal cell carcinoma after radical resection of the metastases. Tumori 100 e28-e30, 2014

12. Grüienwald V, Lin X, Kalanovic D and Simantov R: Early tumor shrinkage (eTS) as a predictive and prognostic factor in metastatic renal cell carcinoma (mRCC). J Clin Oncol 33 (suppl; abstr 4551), 2015

13. Motzer R, Hutson T, Glen H, Michaelson D, Molina AM, Eisen T, Jassem J, Zolnierek J, Maroto P, Mellado B, et al: Randomized phase II, three-arm trial of lenvatinib (LEN), everolimus (EVE) and LEN+EVE in patients (pts) with metastatic renal cell carcinoma (mRCC). J Clin Oncol 33 (suppl; abstr 4506), 2015.

14. Choueiri TK, Figueroa DJ, Fay AP, Signoretti S, Liu Y, Gagnon R, Deen K, Carpenter C, Benson P, Ho TH, et al: Correlation of PD-L1 tumor expression and treatment outcomes in patients with renal cell carcinoma receiving sunitinib or pazopanib: Results from COMPARZ, a randomized controlled trial. Clin Cancer Res 21: 1071-1077, 2015.
15. Armstrong AJ, Broderick S, Eisen T, Stadler WM, Jones RJ, Garcia JA, Vaishampayan UN, Picus J, Hawkins RE, Hainsworth JD, et al: Final clinical results of a randomized phase II international trial of everolimus vs. sunitinib in patients with metastatic non-clear cell renal cell carcinoma (ASPEN). J Clin Oncol 33 (suppl; abstr 4507), 2015.

16. Thoma C: Kidney cancer: CheckMate for advanced-stage ccRCC? Nivolumab and cabozantinib aMETEORate poor survival. Nat Rev Clin Oncol 12: 621, 2015.

17. Michel Ortega RM and Drabkin HA: Nivolumab in renal cell carcinoma. Expert Opin Biol Ther 15: 1049-1060, 2015.

18. Robert C, Long GV, Brady B, Dutriaux C, Maio M, Mortier L, Hassel JC, Rutkowski P, McNeil C, Kalinka-Warzocha E, et al: Nivolumab in previously untreated melanoma without BRAF mutation. N Engl J Med 372: 320-330, 2015.

19. Choueiri TK, Fishman M,Escudier B, McDermott DF, Drake CG, Kluger HM, Stadler WM, Perez-Gracia JL, McNeel DG, Curti BD, et al: Immunomodulatory activity of nivolumab in metastatic renal cell carcinoma. Clin Cancer Res May 11, 2016 (Epub ahead of print).

20. Nadal R, Amin A, Geynisman DM, Martin Voss HM, Weinstock M, Doyle J, Zhang Z, Viudez A, Plimack ER, McDermott DF, et al: Efficacy and safety of endothelial growth factor receptor (VEGFR)-tyrosine kinase inhibitors (TKI) after programmed cell death 1 (PD-1) inhibitor treatment in patients with metastatic clear cell renal cell carcinoma (mccRCC). J Clin Oncol 33: 4566, 2015.

21. Ho TH, Millis SZ, Bryant D, Gatalica Z, Reddy SK, Stanton ML, Castle EP, Joseph RW and Vogelzang NJ: Molecular analysis of sarcomatoid renal cell carcinoma (sRCC). J Clin Oncol 33 (suppl; abstr 4556), 2015.

22. Albiges L, Fay AP, Xie W, Krajewski K, McDermott DF, Heng DY, Dariane C, DeVelasco G, Lester R, Escudier B and Choueiri TK: Efficacy of targeted therapies after PD-1/PD-L1 blockade in metastatic renal cell carcinoma. Eur J Cancer 51: 2580-2586, 2015. 